\title{
Transient Thermal Flux as a Way to Stimulate the Loss Dormancy on Weed Seeds
}

\author{
Carles M. Rubio* \\ Department Agri-Food Engineering and Biotechnology, Polytechnical University of Catalonia, Castelldefels, Spain \\ *Corresponding author: carles.rubio@upc.edu
}

Received June 07, 2013; Revised February 28, 2014; Accepted March 04, 2014

\begin{abstract}
Summertime weeds as Digitaria sanguinalis in many agro-ecosystems exist. In several cases, a welldefined weed control could be able to predict the seed emergence, to know the physiological status of the seeds in the soil bank, as well as, the factors that control and involving their germination. The goal of this work is to establish a relationship between the thermal properties and the process where the seeds start to be viable. In this study, a soil column device refilled with a calcareous silt loam soil was used, and two split seeds groups of Digitaria sanguinalis were buried at two height levels inside the column. The soil was monitored to determine the volumetric water content, temperature and thermal properties. Preliminary results allowed a rather complete understanding of the effect of the thermal flux on Digitaria sanguinalis seeds. The outcomes about the distribution of water content in the soil profile joint to thermal dataset allowed investigating into the variability of these properties and their relationships among them for this type of soil at laboratory scale.
\end{abstract}

Keywords: thermal conductivity, thermal diffusivity, volumetric heat capacity, water content

Cite This Article: Carles M. Rubio, "Transient Thermal Flux as a Way to Stimulate the Loss Dormancy on Weed Seeds.” Applied Ecology and Environmental Sciences, vol. 2, no. 2 (2014): 43-47. doi: 10.12691/aees-2-2-1.

\section{Introduction}

Digitaria sanguinalis is troublesome summer annual weed in many worldwide crops. Seeds are dormant after shedding as well as when they enter the soil bank after displacement [1]. From the point of view of weed control, in order to predict seedling emergences, it will be necessary to know the factors that control seed germination. Several authors such as [2,3,4] cite factors such as water content, bulk density and temperature as the most likely variables to have an effect on the seeds behavior and their relationship with dormancy [5]. But in many cases the probability to change the dormancy status is owing to the where and the how of the process. One of these cases is related to the heat flux. The objective of this work is to observe the relationship between the thermal flux and the germination capacity of the seeds.

\section{Methodology}

In this study, a soil column device constructed specifically for this experiment was used. The device was refilled with a calcareous ( $403 \mathrm{~g} \cdot \mathrm{kg}^{-1}$ ) silt loam soil (sand $340 \mathrm{~g} \cdot \mathrm{kg}^{-1}$, clay $40 \mathrm{~g} \cdot \mathrm{kg}^{-1}$ ), with mean bulk density around $1470 \mathrm{~kg} \cdot \mathrm{m}^{-3}$, and mean total organic carbon content roughly $31 \mathrm{~g} \cdot \mathrm{kg}^{-1}$, obtained between soil surface and 30 $\mathrm{cm}$ depth, from one artichoke crop located at the Llobregat Delta Plain (NE, Spain).

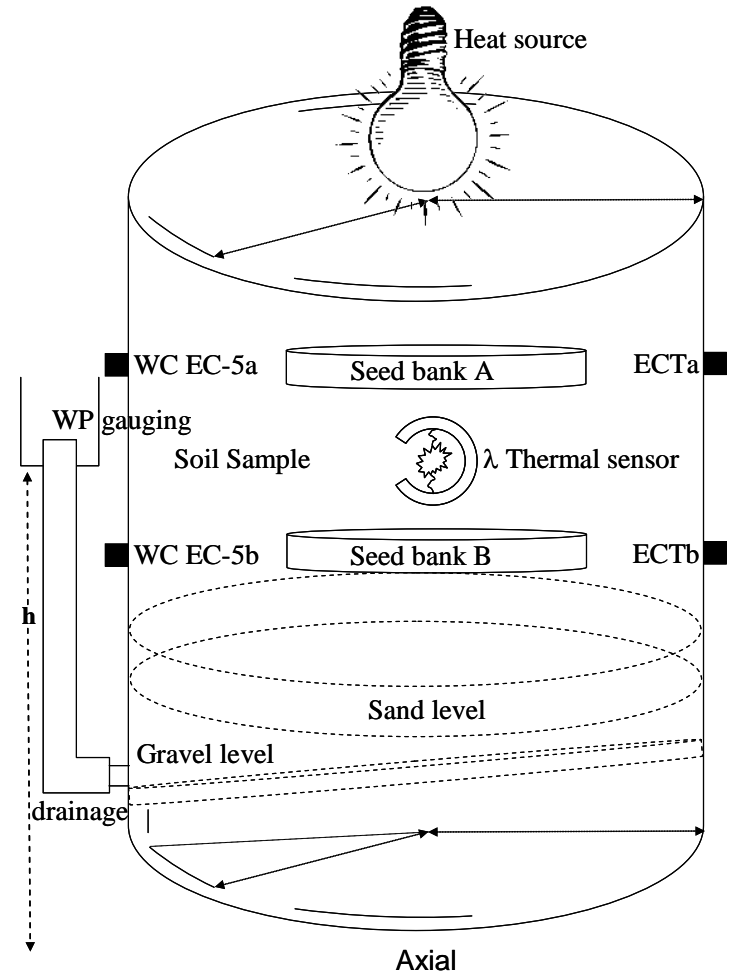

Figure 1. Soil column device scheme used to determine the soil thermal and hydrodynamic properties. WC $=$ FDRs probes to measure water content, $\mathrm{h}=$ distance $(\mathrm{cm})$ of the height of displacement of the separating funnel, $\mathrm{SH}-1$ = thermal sensor to measure thermal properties, ECT =thermal sensor to measure temperature 
The soil column device (Figure 1) had $33 \mathrm{~cm}$ height. From the bottom, the first $3 \mathrm{~cm}$ were refilled with gravels $(4<\varnothing<8 \mathrm{~mm})$. This layer had a support function. The five centimeters above were refilled with fine sand $(250<\varnothing<1000 \mu \mathrm{m})$ to allow (i) a well-drainage, and (ii) a homogeneous wetting up process. The soil layer was constructed using a silt loam soil, which occupied from 25 $\mathrm{cm}$ depth to the top. Two scenarios were sited inside the device, level $\mathrm{A}=4 \mathrm{~cm}$ depth and level $\mathrm{B}=12 \mathrm{~cm}$ depth. Thermal and hydrodynamic properties were monitored at both levels.

To determine the volumetric water content $\left(\mathrm{WC}, \mathrm{m}^{3} \cdot \mathrm{m}^{-3}\right.$ ) two EC-5 frequency domain reflectometry probes, one for each level, were used. Soil temperature $\left(T,{ }^{\circ} \mathrm{C}\right)$ was monitored through ECT soil/air sensor. A Decagon Devices EM-50 data-logger was required to collect the data. To determine the thermal properties one small dualneedle sensor (SH-1) was employed [6]. This kind of sensor use the heat pulse transient method and yield reliable and accuracy soil thermal diffusivity $\left(\alpha, \mathrm{mm}^{2} \cdot \mathrm{s}^{-1}\right)$ and thermal conductivity $\left(\lambda, \mathrm{W} \cdot \mathrm{m}^{-1} \cdot \mathrm{C}^{-1}\right)$ measurements, meanwhile volumetric specific heat $\left(\rho c, \mathrm{MJ} \cdot \mathrm{m}^{-3} \cdot \mathrm{C}^{-1}\right)$ according to relation of both properties was estimated. The SH-1 thermal sensor was placed in the middle of the two levels. Hence, we obtained a data set of soil thermal properties. The data were collected using a KD2-Pro reader-logger.

Also, in both levels two split seeds groups (dormant seeds stored at $-18^{\circ} \mathrm{C}$ since their dispersal time DS; and non-dormant seeds preserved at room temperature NDS) of Digitaria sanguinalis were buried. On the top of the soil a radiation source (50W halogen bulb) was applied during 15 days. The heat and radiation cycles were fitted to 12 hours; they agreed about the quantity of solar hours in our latitude. The radiation involved a thermal gradient between both levels, which was monitored using a thermal sensor. To perform the experiment, the soil sample was wetted up until to reach the half field capacity water content. Moreover, an irrigation cycles were supplied during the experiment. The water supplied involved maintaining the equal moisture for each scenario on the whole of the process.

After 33 days seeds were exhumed. The germination trials were performed at $20^{\circ} \mathrm{C}\left(12 \mathrm{~h}\right.$ darkness) and $30^{\circ} \mathrm{C}$ (12h light). Before incubation, the seeds were rinsed for 10 minutes with 5\% diluted sodium hypochlorite for surface sterilization [7]. Five replicates of 40 seeds placed in $9 \mathrm{~cm}$ diameter plastic Petri dishes were incubated. Illumination was provided by white fluorescent tubes (3x18 W). Three $\mathrm{ml}$ of distilled water was added in each dish at the beginning of the tests. Seeds were considered to be germinated with the emergence of the radicle. Germination counts were carried out for 10 days. The percentages of germination previously arcsine transformation were subjected to analyses of variance followed by Tukey's range test in order to identify homogeneous mean groups [8]. Tukey's test is essentially a t-test, except that it corrects for experiment-wise error rate. Therefore, it is more suitable for multiple comparisons that doing a number of t-tests would be (see eq. 1).

$$
q_{S}=\frac{\left(Y_{A}-Y_{B}\right)}{S E}
$$

Where $Y_{A}$ is the larger of the two means being compared, $Y_{B}$ is the smaller of the two means being compared, and $S E$ is the standard error data in question. This $q_{s}$ value can then be compared to a $q$ value from the studentized range distribution. If the $q s$ value is larger than the $q$ critical value obtained from the distribution, the two means are said to be significantly different.

To wrap up the whole experiment, an estimation of thermal damping depth was calculated. Damping depth is a constant characterizing the decreased in thermal amplitude with an increase in distance from the soil surface [14]. Calculations were performed following the equation 2.

$$
d=\left(\frac{2 \alpha}{\omega}\right)^{0.5}
$$

Where $\alpha$, is the thermal diffusivity, and $\omega$ is the angular frequency of temperature fluctuations at the surface. The value of the damping depth will be key to predicting the penetration into the soil of a temperature variation at the surface $[11,16]$. Therefore, this relationship (eq. 2) is useful for getting a general idea of how soil temperature varies with depth and time. However, the use of this model assumes uniform soil properties throughout the soil profile and a sinusoidally varying surface temperature.

\section{Results and Discussion}

Table 1 shows the results of the soil variables monitored inside the device. Mean water content at level A was higher than level B, with differences about 2.5\% $\left(\mathrm{vol} \cdot \mathrm{vol}^{-1}\right)$. Average temperature values showed that this variable was at steady-state during all experimental process, and close to temperature room values $\left(20.4{ }^{\circ} \mathrm{C}\right)$. The thermal integral between both levels presented differences about $15^{\circ} \mathrm{C}$, always higher for level $\mathrm{A}$, also in the maximum temperature values $\left(\mathrm{A}=27.9^{\circ} \mathrm{C} ; \mathrm{B}=22.9^{\circ} \mathrm{C}\right)$. Thus, the radiation source created a slight thermal gradient inside the device. On the other hand, thermal properties showed an homogeneous values, except the volumetric specific heat, with differences about $0.5 \mathrm{MJ} \cdot \mathrm{m}^{-3} \cdot \mathrm{C}^{-1}$. In fact, it was owing to the complex moisture scenarios between both levels [9].

Table 1. Statistical variables determined for the soil dataset obtained from the column device. Avg: average, Int: integral. (See text for legend)

\begin{tabular}{ccccccccc}
\hline & $\lambda$ & $\rho c$ & $\alpha$ & $\begin{array}{c}\text { WC } \\
\text {-A }\end{array}$ & $\begin{array}{c}\text { WC } \\
\text {-B }\end{array}$ & T-A & T-B & T lab \\
\hline Avg. & 0.55 & 2.08 & 0.26 & 0.13 & 0.11 & 21.2 & 20.5 & 20.4 \\
Max. & 0.63 & 2.34 & 0.29 & 0.16 & 0.12 & 27.9 & 22.9 & 22.8 \\
Min. & 0.50 & 1.88 & 0.26 & 0.10 & 0.09 & 17.8 & 18.4 & 18.1 \\
Int. & ---- & ---- & ---- & ---- & ---- & 568.3 & 551.2 & 507.5 \\
\hline
\end{tabular}

Table 2, shows the results of the Pearson correlation among the thermal and hydraulic variables studied. On the whole, most of variables had an acceptable correlation, especially thermal conductivity versus volumetric specific heat. The value obtained for the coefficient was 0.963 for $\mathrm{p} \leq 0.01$. Thus, the transient thermal flux for this type of soil, according to the specific water content conditions was enough to transmit and storage a quantity of heat on the soil matrix, which could affect the seeds bank [10]. 
Table 2. Correlation among thermal and hydrodynamics variables. The correlation was significant at the 0.01 level (2-tailed). (See text for legend)

\begin{tabular}{cccccccc}
\hline & $\lambda$ & $\rho \mathrm{c}$ & $\alpha$ & WC-A & WC-B & T-A & T-B \\
\hline$\rho \mathrm{c}$ & .963 & & & & & & \\
$\alpha$ & -.486 & -.703 & & & & & \\
WC-A & .867 & .864 & -.529 & & & & \\
WC-B & .876 & .826 & -.364 & .680 & & & \\
T-A & -.494 & -.660 & .836 & -.395 & -.376 & & \\
T-B & -.528 & -.685 & .828 & -.430 & -.367 & .795 & \\
$\mathrm{~T}_{\text {lab }}$ & -.497 & -.636 & .757 & -.368 & -.315 & .827 & .890 \\
\hline
\end{tabular}

The dynamic of the variables water content and temperature are showed in Figure 2. The probe placed in WC-B exhibited the lowest water content over the whole period even when the temperature was higher on the top of the soil. However, the level B remained more stable than level A, although the bulb had turned on until the end of the experiment.

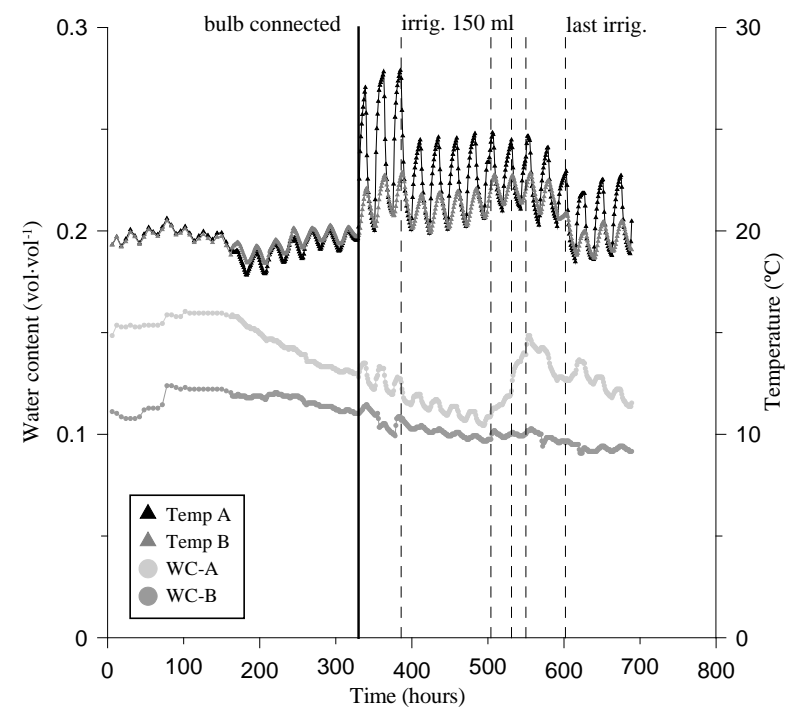

Figure 2. Behavior of the temperature and water content in the soil column device, before and after to star the irrigation process, and to switch on the additional heat source

On the other hand, at level A the effect of the additional heat source was obvious. Several peaks of temperature reached on the soil surface affected directly the water content. These peaks could be related on one hand with the evaporation process inside the column device, and on the other hand the peaks could be related with the effect of the temperature over the EC-5 probe $[9,10]$. To avoid the total loss of water provoking physiological consequences for the seeds, the water consumption was supplied with additional irrigation events (dot lines). Every dot line provides a $150 \mathrm{ml}$ of water, except at the point 550 hour, where provided the soil with $115 \mathrm{ml}$ of water. The evaporation rates were minimized with a wet filter paper on the surface of the soil.

As far as the temperature is concerned, the variable presented higher increases at the layer A, especially at the beginning of the experiment, when soil was dry. The thermal damping depth shown high evidences between two layers (A and B). The soil worked as a buffer [11,13] lessening the transfer of the heat flux in the deepest layers of the soil.

The environment experienced by the DS during the burial period was reflected in their germination capacity
(Figure 3). Dormant seeds placed at $4 \mathrm{~cm}$ (A) differed significantly from seeds bank B (12 cm depth) in their cumulative germination percentage from DS control (83.5\% and $87 \%$, respectively, versus $1.5 \%)$. There were no statistical differences between buried DS with respect the depth position. The period of time lasted in the experiment was sufficient to break dormancy of the seeds simulating freshly dispersed situation. However, in comparison with NDS, both DS splits (A and B) did not reach the $100 \%$ of cumulative germination (significant differences between DS and NDS for each depth position and for control as well) [12].

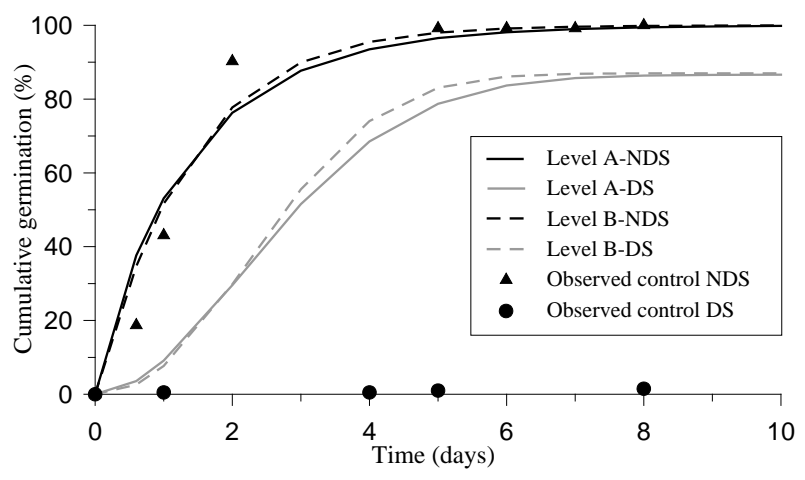

Figure 3. Evolution of the cumulative percentage of germination on Digitaria sanguinalis seeds after the burial period

Figure 4, shows how the surface temperature wave is attenuated with depth and shifted in time inside the column device. The values used to obtain the damping depth were taken from the Table 1 . The fact to use a bulb involved a well-defined thermal damping depth, which simulated the environmental conditions in hour latitude. However, soil temperature fluctuates annually and daily affected mainly by variations in air temperature [17]. This laboratory experiment avoided this variable having the soil column device inside of isothermal chamber. Dramatic changes were probably due to the nearest of the bulb to the soil surface. On the other hand, continuous moisture on the soil surface minimized the effect of the temperature, where the maximum temperature peak of heat was low than the obtained by the model.

Consequently, the low value of thermal diffusivity provided more than $5^{\circ} \mathrm{C}$ of attenuation between the two seeds levels, i. e. when at $4 \mathrm{~cm}$ depth reached the maximum temperature around 16 hours, the temperature at the deepest level with seeds had only increased $3{ }^{\circ} \mathrm{C}$ from their initial temperature conditions. An important factor to affect the thermal diffusivity is the water content. For mineral soils $\alpha$ increases with water content at low water contents, even though $\alpha$ gradually decreases with increasing water contents at high water contents $[18,19,20]$. In fact, that is the impact of water content upon the soil temperature, which governs the three thermal properties. Besides, bulk density and mineral particles are important variables, yet in the experiment were not decisive, because they did not vary on the spatial-temporal pattern.

Regarding the weed seeds, they were buried at correct depths, usually 1 and $5 \mathrm{~cm}$ [21]. According to Dawson and Bruns and Defelice [22,23], the maximum reported depth for emergence was about $12 \mathrm{~cm}$. On the other hand, the most important environmental parameter reported to affect the dormancy/ non-dormancy cycle of most summer 
annual species is temperature [24,25]. Accordingly, the seeds of this specie require exposure to low winter temperatures to emerge from dormancy. In spring and early summer, the seeds are non-dormant and ready to germinate under favourable conditions $[21,26]$. Such as it is shown in Figure 4, the seeds banks were on the range determined for their germination [27]. Yet they probably did not acquire the necessary days-degree to germinate. The water content storied in the soil presented a continuous and decreasing effect of the temperature over the seeds; it prevented the $100 \%$ of their germination.

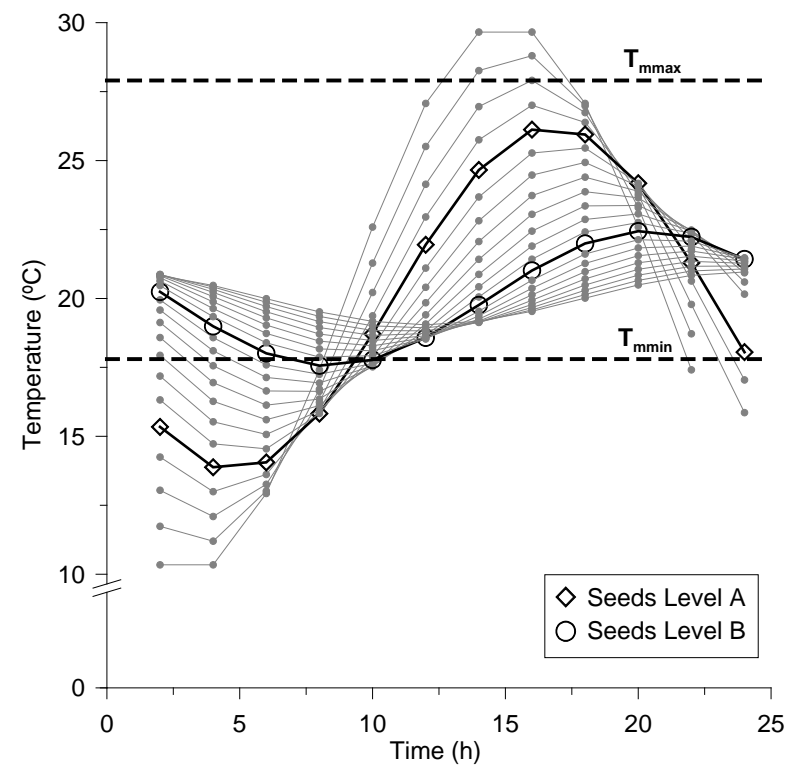

Figure 4. Estimation of the thermal damping depth. Dot lines show the mean minimum (Tmmin) and mean maximum (Tmmax) temperature threshold during the experiment

\section{Conclusions}

After a period of 33 days, in the monitored microenvironmental conditions of the experimental column device, an important fraction of the DS buried seeds lost the dormancy. Furthermore, the high resolution of the used sensors allowed measuring the minimal spatial differences for the water content and temperature variables between both levels. It would be related to smaller differences observed in the rate of germination of pre-dormant seeds. The main recommendation and outlook would be to investigate the environmental differences between the two scenarios inside the soil column device, since in this research Digitaria sanguinalis seeds had not obtained the same mean accumulative percentage of germination. Despite the fact that the values were different, the differences between both environments (A and B) were not statistically significant. On the other hand, a higher value of thermal diffusivity had allowed increasing the temperature in the deepest level, and probably a quantity of seeds germination had been higher.

\section{Acknowledgements}

Ongoing research on water plant relationship was supported by the Ministry of Science and Innovation. The first author benefited from a post-doctoral grant award while carried out this research. Also, I thank to Dr. R. Josa for your fruitful discussions, and Drs. A. Verdu and M. Mas for their help with weeds and Tukey's test.

\section{References}

[1] Gallart M., Verdu A, Mas M. (2008). Dormancy breaking in Digitaria sanguinalis seeds: the role of the caryopsis covering structures. Seed Science and Technology 36 (2): 259-270.

[2] Sperling L. (2002). Emergency seed Aid in kenia: Some case study insights on lessons learned during the 1990s. Disasters Special issue: Beyond seeds and tools. Vol. 26:4, 329-342.

[3] Alvarez R., Quintero I., Manzano Mendez J., Gonzalez D. (2009). Emergency and seedlings characteristics from Chrysophyllum cainito L. under differents preemergence treatments and sowing seed position. Rev. Cientif. UDO Agrícola. Univ. Oriente Press, Vol. 9:2, 333-342.

[4] Felippi M., Grossi F., Nogueira A., Kunisyoshi, Y. (2008). Fenologia e germinaçao de sementes de agual Chrysophyllum gonocarpum. (Mart \& Eichl.) Engl. Floresta 38:2, 229-243.

[5] Baskin, C., Baskin, J. 2001. Seeds.Ecology, Biogeography, and Evolution of Dormancy and Germination. Academic Press, San Diego, USA, p. 666.

[6] Rubio C.M., Ferrer F, Josa R. 2008. Thermal properties as a function of water content in a silt porous media under laboratory conditions. Proceed. 15th International Congress of ISCO. 1:107.

[7] International Seed Testing Association 1985. International rules for seed testing. Rules and annexes. Seed Science and Technology, 13: 299-515.

[8] SAS Institute Inc. 1999. SAS OnlineDoc ${ }^{\circledR}$, Version 8, Cary, NC: SAS Institute Inc.

[9] Parsons L.R., Bandaranayake W.M. (2009) Performance of a new capacitance soil moisture probe in a sandy soil. SSSA Journal 73:4, 1378-1385.

[10] Sakaki T., Limsuwat A., Smits K.M., Illangasekare T.H. (2008) Empirical two-point alpha-mixing model for calibrating the ECHO2 EC-5 soil moisture sensor in sands. Water Resour. Res. 44, W00D08.

[11] Campbell GS, Norman JM (Eds) (1998) An introduction to environmental biophysics. 2nd ed. Springer-Verlag, NewYork.

[12] Rubio, C.M.; Mas, M.; Verdú, A.M.; Gallart, M.; Ferrer; F.; Josa, $R$ (2008). Effect of a transient thermal flux on the dormancy of Digitaria sanguinalis seeds. Italian Journal of Agronomy. Vol. 3, 3:707-708.

[13] Rubio, C.M., Ubeda, X., Ferrer, F. (2012) Response of the thermal conductivity as a function of water content of a burnt Mediterranean Loan Soil. J. Soil Science, 2,2

[14] Hillel D., (1982) Introduction to soil physics. Academic Press, San Diego, CA, USA.

[15] Marshall T.J., Holmes J.W. (1988) Soil Physics. 2nd ed. Cambridge Univ. Press, New York.

[16] Campbell G.S. (1988) Soil Physics with Basic. 2nd ed. Elsevier Sciencies Pub. Development in Soil Science 14, The Netherlands.

[17] Wu J., Nofziger, D.L. (1999) Incorporating temperature effects on pesticide degradation into a management model. J. Environmental Qual., 28, 92-100.

[18] DeVries D.A. (1975) Heat Transfer in Soils. In D.A. DeVries and N.H. Afgan (ed) Heat and Mass Transfer in the Biosphere. Scripta Book Co., Washington, DC, pp. 5-28.

[19] DeVries D.A. (1963) Thermal Properties of Soils. In W.R. van Wijk (ed.) Physics of Plant Environment. North-Holland Publishing Company, Amsterdam.

[20] Farouki O.T. (1986) Thermal Properties of Soils. Series on Rock and Soil Mechanisc. Vol. 11 Trans Tech Publ., ClausthalZellerfeld, Germany.

[21] Dekker J. (2003) The foxtail (Setaria) species-group. Weed Science, 51, 641-656.

[22] Dawsoon J.H., Bruns V.F. (1975) longevity of barnyardgrass, green foxtail, and yellow foxtail seeds in soil. Weed Science 23, 437-440.

[23] Defelice M.S. (2002) Green foxtail, Setaria viridis (l.) P. Beauv. Weed Technology 16, 253-257.

[24] Schonbeck M.W., Egley G.H. (1981) Changes in sensitivity of Amaranthus retroflexus L. seeds to ethylene during pre-incubation. 
II. Effects of alternating temperature and burial in soil. Plant, Cell and Environment 4, 237-242.

[25] Baskin C.C., Baskin J.M., El Mourset S.A. (1997) Seasonal changes in germinatin respnses of buried seeds of the weedy summer annual grass Setaria glauca. Weed research 36, 319-324.
[26] Baskin C.C., Baskin J.M. (1998) Seeds. Ecology, Biogeography, and Evolution of Dormancy and Germination. Academic Press Inc, San Diego, CA, USA.

[27] Masin R., Zuin M.C., Otto S., Zanin G. (2006) Seed longevity and dormancy of four summer annual grass weeds in turf. Weed Research, 46, 362-370. 